\title{
O PROGRAMA CONEXÕES DE SABERES COMO POLÍTICA AFIRMATIVA NO CONTEXTO DO SEMIÁRIDO NORDESTINO: O caso da UFERSA em Mossoró/RN
}

\author{
Marcos Augusto de Castro Peres ${ }^{1}$ \\ Ady Canário de Souza ${ }^{2}$
}

\section{RESUMO}

Este texto analisa a experiência pioneira do Programa de Extensão Conexões de Saberes no âmbito da Universidade Federal Rural do Semiárido (UFERSA), campus de Mossoró/RN, ao longo do ano de 2010. Como fonte, foram utilizados os questionários preenchidos pelos estudantes no processo de seleção para a bolsa do Programa. Os resultados demonstram que, apesar dos problemas inerentes às políticas de ação afirmativa, o Programa Conexões de Saberes tem sido importante para promover a inserção de estudantes de origem popular nas universidades públicas. Itens como raça, cor, gênero, renda familiar e região de origem (rural/urbana) ainda são determinantes no acesso e na permanência dos estudantes no ensino superior brasileiro, especialmente nas universidades públicas. Em paralelo, as peculiaridades do semiárido nordestino (área tradicionalmente marcada pela miséria social), atuam como elementos agravantes da exclusão, constituindo mais um desafio a ser enfrentado pelas políticas afirmativas.

Palavras-chave: Ensino superior; extensão universitária; políticas afirmativas; exclusão educacional; exclusão social; semiárido.

\section{THE UNIVERSITY EXTENSION PROGRAM “CONEXÕES DE SABERES” HOW POLICY AFFIRMATIVE IN THE CONTEXT OF NORTHEASTERN SEMIARID: The case of UFERSA, Mossoró/RN}

\begin{abstract}
This paper analyzes the pioneering experience of the University Extension Program "Conexões de Saberes" within the Universidade Federal Rural do Semiárido (UFERSA), in Mossoró/RN, along the year 2010. As a source of data, we used questionnaires completed by students in the selection process for the scholarship program. The results demonstrate that, despite the problems of the affirmative action policies, the Program "Conexões de Saberes" has been important to promote the inclusion of low-income students in public universities. Items such as race, color, gender, household income and source region (rural/urban) are still determining the access and the stay of students in higher education in Brazil, especially in public universities. Moreover, the peculiarities of the semiarid Northeast (a region traditionally characterized by social deprivation), act as aggravating factors of exclusion and is another challenge to be faced by the affirmative policies.

Keywords: Hider education, university extension, affirmative policies, educational exclusion, social exclusion, semiarid.
\end{abstract}




\section{O Programa Conexões de Saberes: breve histórico e definição}

O Ministério da Educação, através da Secretaria de Educação Continuada, Alfabetização e Diversidade (SECAD), em parceria com o Observatório de Favelas, implantou no fim de 2004 o Programa Conexões de Saberes, inicialmente em cinco universidades públicas brasileiras (UFF, UFRJ, UFMG, UFPE, UFPA). A partir de junho de 2005 o Programa foi estendido para outras nove universidades (UFES, UnB, UFMS, UFPR, UFRGS, UFPB, UFC, UFBA, UFAM) e em 2006 ampliado para mais 18 universidades (UFAC; UFAL; UFG; UFMA; UFMT; UFPI; UFRN; UFRPE; UFRR; UFRRJ; UFS UFSC; UFSCar; UFT; UNIFAP; UNIR, UNIRIO, UNIVASF). O Programa Conexões de Saberes está presente hoje em mais de 30 universidades públicas em todo o país, tendo a Universidade Federal Rural do Semi-Árido (UFERSA) aderido a ele no final do ano de 2010.

O objetivo maior do Programa Conexões de Saberes é ampliar a relação entre a universidade $\mathrm{e}$ as comunidades populares, promovendo o encontro e a troca de conhecimentos e experiências entre estes duas esferas socioculturais. Neste programa, busca-se a permanência e a participação protagonista do estudante de origem popular na vida universitária, na produção de conhecimento sobre sua realidade de estudo e de moradia, além de criar condições para a transformação institucional da universidade. Em síntese, o Programa Conexões de Saberes funciona da seguinte forma: cada instituição participante do Programa seleciona um mínimo de 25 estudantes para atuarem como bolsistas de extensão e desenvolverem as atividades relativas ao Programa, que abrangem desde a participação em cursos de formação até a prática da docência em cursos preparatórios para o vestibular do Exame Nacional do Ensino Médio (ENEM), ministrados em escolas públicas estaduais de ensino médio, na cidade onde fica o campus da universidade executora do programa.

\section{O semiárido como área de exclusão social e educacional}

No caso da UFERSA, campus central, a escola escolhida como representante das comunidades populares do entorno foi a Escola Estadual Aída Ramalho, em Mossoró, no Rio Grande do Norte. Merece destaque o fato de que a UFERSA se tornou universidade recentemente, mais precisamente em 2005, como parte do programa de reestruturação universitária (REUNI) promovido pelo governo federal. Além disso, a UFERSA é uma instituição federal de ensino superior (IFES) localizada no interior do estado do Rio Grande do Norte, em uma região bastante carente: o semiárido. ${ }^{3}$ E é por isso que ela é classificada como uma universidade federal rural, abrangendo, além de Mossoró, também as cidades de Angicos e Caraúbas. Essa experiência do Programa Conexões de Saberes da qual participamos e agora analisamos significa a primeira ação de política afirmativa na história desta instituição, que, até o ano de 2004, era conhecida como Escola Superior de Agronomia de Mossoró (ESAM). Criada no contexto da ditadura militar em 1967, a ESAM atenderia às demandas por mão-de-obra qualificada de empresas da região, especialmente as ligadas à produção agropecuária em expansão.

A Escola Aída Ramalho está localizada no mesmo bairro do campus central da UFERSA, em Mossoró, chamado de Costa e Silva. É uma escola estadual tradicional na cidade, com alunos provenientes de classes populares. Percebe-se que o principal objetivo da maioria dos alunos da Aída é o de se tornar aluno da UFERSA. Por isso, o curso préuniversitário do Programa Conexões de Saberes da UFERSA teve muito boa aceitação 
entre os alunos selecionados desta escola. Além disso, os próprios critérios de seleção dos alunos participantes do pré-universitário utilizados pelo programa procuram priorizar realmente os mais necessitados, pois consideram fatores como renda familiar, escolaridade dos pais, cor ou raça, origem rural ou urbana, trajetória educacional realizada em escola pública, dentre outros. É importante destacar que estes mesmos critérios também são utilizados no processo de seleção dos alunos bolsistas para integrar o Programa Conexões de Saberes dentro das universidades.

\begin{tabular}{|c|l|c|c|c|}
\hline \multicolumn{5}{|c|}{ Tabela 1 - Alfabetização e situação de domicílio (rural/urbana) } \\
\hline \multicolumn{5}{|c|}{ Variáveis: pessoas de 5 anos ou mais de idade - Ano 2000 } \\
\hline \multirow{3}{*}{ Brasil e UF } & Sit. domicílio & População total & $\begin{array}{c}\text { Não } \\
\text { alfabetizados }\end{array}$ & $\begin{array}{c}\text { Porcentagem de } \\
\text { não alfabetizados }\end{array}$ \\
& Total & 153.486 .617 & 24.093 .776 & $16 \%$ \\
\cline { 2 - 5 } & Urbana & 125.175 .892 & 15.391 .771 & $12,30 \%$ \\
\cline { 2 - 5 } & Rural & 28.310 .725 & 8.702 .005 & $22,70 \%$ \\
\hline \multirow{3}{*}{ Rio Grande do } \\
Norte & Total & 2.498 .980 & 650.371 & $26 \%$ \\
\cline { 2 - 5 } & Urbana & 1.838 .818 & 394.005 & $21,40 \%$ \\
\cline { 2 - 5 } & Rural & 660.162 & 256.366 & $38,80 \%$ \\
\hline
\end{tabular}

Fonte: IBGE, Censo 2000.

A Tabela 1 mostra que, no estado do Rio Grande do Norte, o analfabetismo é um problema predominantemente rural, apesar de ocorrer também nas áreas urbanas, em proporção maior do que a média nacional, em ambos os casos. Além disso, a porcentagem de pessoas de 5 anos ou mais que não são alfabetizadas no Rio Grande do Norte (de 26\%) é superior à média total nacional (16\%). Neste estado, o analfabetismo atinge 21,4\% na zona urbana e de $38,8 \%$ na zona rural, enquanto que, no Brasil, os índices são de $12,3 \%$ e de $22,7 \%$, respectivamente. Estes dados revelam a maior precariedade dos sistemas educacionais no Rio Grande do Norte. Situação esta que piora conforme o grau de desenvolvimento urbano da cidade, ou seja, quanto menos urbanizada é a cidade, maior a sua porcentagem de analfabetos. 


\begin{tabular}{|c|l|c|c|c|}
\hline \multicolumn{5}{|c|}{ Tabela 2 - População residente por nível de alfabetização e grupos de idade } \\
(Ano 2000) \\
\hline $\begin{array}{c}\text { Municípios do } \\
\text { RN }\end{array}$ & \multicolumn{1}{|c|}{$\begin{array}{c}\text { Grupos de } \\
\text { idades }\end{array}$} & $\begin{array}{c}\text { População } \\
\text { total }\end{array}$ & $\begin{array}{c}\text { Não } \\
\text { alfabetiz. }\end{array}$ & $\begin{array}{c}\text { Porc. não } \\
\text { alfabetizados }\end{array}$ \\
\hline \multirow{5}{*}{ Natal } & 10 a 14 anos & 72.195 & 5.294 & $7,33 \%$ \\
\cline { 2 - 5 } & 25 a 29 anos & 59.253 & 4.673 & $7,88 \%$ \\
\cline { 2 - 5 } & 35 a 39 anos & 55.275 & 5.616 & $10,16 \%$ \\
\cline { 2 - 5 } & 45 a 49 anos & 35.554 & 4.824 & $13,56 \%$ \\
\cline { 2 - 5 } & 60 anos ou mais & 56.269 & 17.438 & $31,00 \%$ \\
\hline \multirow{5}{*}{ Mossoró } & 10 a 14 anos & 23.487 & 1.883 & $8,01 \%$ \\
\cline { 2 - 5 } & 25 a 29 anos & 18.040 & 2.224 & $12,32 \%$ \\
\cline { 2 - 5 } & 35 a 39 anos & 16.832 & 2.975 & $17,67 \%$ \\
\cline { 2 - 5 } & 45 a 49 anos & 9.336 & 2.317 & $24,81 \%$ \\
\cline { 2 - 5 } & 60 anos ou mais & 16.510 & 7.988 & $48,38 \%$ \\
\hline \multirow{5}{*}{ Angicos } & 10 a 14 anos & 1.489 & 185 & $12,42 \%$ \\
\cline { 2 - 5 } & 25 a 29 anos & 771 & 174 & $22,56 \%$ \\
\cline { 2 - 5 } & 35 a 39 anos & 778 & 245 & $31,49 \%$ \\
\cline { 2 - 5 } & 45 a 49 anos & 473 & 212 & $44,82 \%$ \\
\cline { 2 - 5 } & 60 anos ou mais & 1.340 & 859 & $64,00 \%$ \\
\hline
\end{tabular}

Fonte: IBGE, Censo 2000.

Essa disparidade pode ser observada na Tabela 2, que compara as taxas de analfabetismo entre os municípios de Natal, Mossoró e Angicos. Em Natal - que é a capital do estado e dispõe, portanto, de uma melhor infraestrutura de serviços educacionais - podemos ver uma proporção menor de pessoas não alfabetizadas, em todos os grupos de idade, quando comparados a Mossoró e Angicos. No entanto, quando comparamos Mossoró a Angicos, este último apresenta taxas mais elevadas de analfabetismo, exatamente pelo fato de ser menos urbanizado do que Mossoró.

Dessa forma, nota-se que quanto mais "sertaneja" é a localidade em questão, mais precária é a estrutura de acesso aos direitos sociais, como educação, saúde, etc. A idéia de cidadania, cuja origem etimológica remonta à Grécia Antiga, compreende a cidade como espaço de participação política e de acesso aos direitos. Desde o surgimento da civitas, o meio urbano se diferencia do rural, exatamente por concentrar o desenvolvimento. É, em síntese, o lócus da civilização. O campo, ao contrário, representa o atraso, o arcaico, uma realidade social a ser superada inevitavelmente pela expansão do modo de produção urbano-industrial da sociedade capitalista. Mesmo no marxismo, o campesinato é visto como uma categoria deslocada dentro do capitalismo, por não deter a força de resistência e mobilização que é peculiar ao operariado industrial. As relações de trabalho no campo não acompanharam a dinâmica do modo de produção capitalista, resultante do processo de industrialização (FABRINI, 2005).

Assim, é relativamente fácil entender porque os direitos políticos, sociais e individuais são vivenciados precariamente no meio rural. Direito, Estado e civilização sempre caminharam juntos, tal como cidade e cidadania. O campo foi historicamente excluído do conjunto de direitos conquistados pela sociedade capitalista. No Brasil, o meio urbano, a cidade, e principalmente as capitais dos estados, continuam sendo espaços onde a 
educação, a saúde e os demais direitos são oferecidos com efetividade, possuindo abrangência e qualidade muito superior do que nos interiores.

O sertão é conhecido, portanto, como o "lugar da ausência" - nele falta tudo: falta desenvolvimento, falta água, falta humanização, faltam direitos, etc. A genial (e imortal) obra literária de Graciliano Ramos (2008) já mostrava que a vida do sertanejo, especialmente nas regiões semiáridas, é uma "vida seca", ou seja, é uma "vida sem vida", sem dignidade, sem esperança. É uma vida de seres humanos que não se sentem humanizados (lembrando que, no romance, a cachorra Baleia é "mais humana" do que Fabiano e sua família), em virtude da degradante exclusão social. A civilidade, necessária à convivência social nas sociedades desenvolvidas, é, não raro, algo distante para o sertanejo. É praticamente inatingível. Os muitos "Fabianos" que aí vivem não conseguem se comunicar e nem compreender o mundo das cidades. Eles apenas o temem, tal como ao "soldado amarelo".

Mas quem são os sertanejos no Brasil? Qual o perfil das populações humanas que vivem no campo? Para Roseli Caldart (2008), são considerados povos do campo os trabalhadores rurais, os pequenos agricultores, os bóias-frias, os meeiros, os posseiros, os indígenas, os quilombolas, os pescadores, os caiçaras, os extrativistas, os boiadeiros, os peões, dentre outros. Nessa população, predominam pessoas da cor parda e negra e com baixa renda familiar. Na verdade, as regiões Nordeste e Norte, com exceção das capitais dos estados, podem ser consideradas como um "grande sertão", pelo tipo de colonização aí vivenciada, pelo clima desfavorável e pelo perfil étnico-racial da população local. Explica Albuquerque Jr. (1999), em A invenção do Nordeste e outras artes, que: "O Nordeste (...) estava condenado [à decadência] pelo caráter mestiço de sua raça e também pela tropicalidade de seu clima" (p. 58).

Assim, o clima seco e a miscigenação racial do Nordeste seriam vistos, desde a colonização, como entraves para o desenvolvimento do país. De certa forma, a presença do negro e do índio na composição étnico-racial do nordestino contrastaria com a suposta "superioridade" do branco europeu que colonizou as regiões Sudeste e Sul. O atraso do Nordeste era reconhecido em contraponto com o desenvolvimento do Sudeste-Sul, especialmente de São Paulo. O próprio Nordeste, na verdade, é "inventado" a partir desta oposição Norte/Sul, que representa simbolicamente o contraste entre um Brasil miscigenado, mestiço, e um Brasil branco, europeu, entre miséria e opulência, entre atraso e desenvolvimento, entre sertão e cidade (ALBUQUERQUE JR., 1999).

\section{A exclusão educacional e as dicotomias rural/urbano, campo/cidade e sertão/capital}

Não é novidade que o nosso sistema educacional está focado prioritariamente na vida nas cidades. Como a atual educação escolar foi estruturada com a emergência da sociedade urbano-industrial capitalista, não é de se estranhar que o meio rural ficasse relegado ao esquecimento, na condição de mero "apêndice" da vida urbana. O resultado disso é a construção de uma educação centrada na vida da cidade e distante da vida no campo. E esse distanciamento se revela tanto nos currículos e conteúdos adotados (geralmente contextualizados à vida urbana e desconectados da dinâmica da vida rural), quanto pela precariedade das escolas disponíveis no campo.

Acredito não ser possível tratar de assuntos como política afirmativa e inclusão educacional sem trazer à tona um grande problema relativo à educação brasileira: o déficit educacional e o analfabetismo, que atingem, ainda, uma parcela significativa da população. O Censo 2010 mostrou que há 13,9 milhões de analfabetos com 15 anos ou mais no Brasil. 
Dentre as diversas regiões do país, a região Nordeste é a pior de todas, apresentando o índice de $19,1 \%$ de analfabetos. No Sudeste a proporção de analfabetos é de 5,5\%, no Sul de $5,1 \%$, no Centro-Oeste $7,2 \%$ e no Norte $11,2 \%$.

Não sem motivo, é no meio rural que encontramos os mais baixos índices de escolaridade de toda a sociedade brasileira. Os dados do INEP, sistematizados no trabalho Panorama da Educação do Campo (2007), mostram que a escolaridade média da população de 15 anos ou mais que vive no meio rural brasileiro, que é de 3,4 anos, corresponde à quase metade da estimada para a população urbana, que é de 7,0 anos. Se os índices de analfabetismo no Brasil são bastante elevados, no meio rural esses indicadores são ainda mais preocupantes. Segundo o IBGE (Censo 2000), 29,8\% da população adulta de 15 anos ou mais -, que vive no meio rural é analfabeta, enquanto no meio urbano essa taxa é de 10,3\%. É importante ressaltar que a taxa de analfabetismo aqui considerada não inclui os analfabetos funcionais, ou seja, aquela população com menos de quatro séries do ensino fundamental. Outros dados revelam ainda que no meio rural brasileiro, $6 \%$ das crianças, de 7 a 14 anos, encontram-se fora dos bancos escolares; que apesar de 65,3\% dos jovens, de 15 a 18 anos, estarem matriculados, $85 \%$ deles apresentam defasagem de idadesérie, o que indica que eles ainda permanecem no ensino fundamental; e que somente $2 \%$ dos jovens que moram no campo frequentam o ensino médio.

Esses são alguns dos indicadores que demonstram a histórica negação do direito à educação no Brasil, principalmente para a população rural. O que engrossa as estatísticas de analfabetismo é, portanto, o problema histórico do acesso à educação (fundamental e média) verificado no meio rural. Contudo, é bom lembrar que a exclusão educacional não é um problema restrito à população adulta e mais velha, mas um problema crônico do próprio sistema, pois novos analfabetos são gerados a cada dia no Brasil, quando contingentes de crianças e jovens são excluídos do acesso e da permanência na educação fundamental e média, por diversos motivos (como, por exemplo, ausência de escolas, falta de transporte coletivo, necessidade de trabalhar, fome, falta de merenda escolar e muitos outros determinantes da evasão escolar).

O déficit educacional entre adultos, observado particularmente nos países subdesenvolvidos, decorre, sobretudo, da ausência ou insuficiência de oferta educacional, principalmente nas regiões menos desenvolvidas do país, como as áreas rurais e sertanejas. O trabalho rural, executado pelo "camponês" ou "homem do campo", está associado historicamente à exclusão da educação formal. O trabalho industrial, ao contrário, conectase aos chamados "conhecimentos superiores", à ciência e à técnica, inerentes à vida urbana.

Assim, os “cidadãos", na Grécia Antiga, eram aqueles que tinham propriedade, e que, por isso, podiam ter acesso à cidade da Pólis, tida como centro de decisões e deliberações políticas e de reflexão filosófica. A própria palavra: "civilizado" é derivada de civitas, ou seja, refere-se àquele que vive nas cidades e tem acesso à participação política e ao pensamento filosófico e racional, que figuram como processos e relações produzidos neste espaço. A industrialização, ocorrida a partir do século XVIII na Europa, potencializaria ainda mais a oposição entre rural e urbano, no que se refere ao acesso à educação formal, pois se tornava necessário educar para o trabalhado industrial característico das cidades e do "mundo civilizado". O campo, por sua vez, ficaria excluído do projeto capitalista de educação na sociedade industrial que emergia. Dessa forma, é interessante notar que o "homem educado" da sociedade moderna seria conhecido como sinônimo de "homem civilizado", "polido", ao passo que designações depreciativas como as de "atrasado", "ignorante", "matuto", "xucro", "simplório", "peão", "caipira", etc., seriam associadas ao "homem do campo", ao "sertanejo". 
É necessário lembrar que, no sertão semiárido brasileiro, a precariedade e a exclusão normalmente vivida no campo são potencializadas em virtude das maiores dificuldades ambientais, sociais e infraestruturais aí existentes. Etimologicamente, sabe-se que a palavra "sertão" teve sua origem histórica durante a colonização do Brasil pelos portugueses. Ao saírem do litoral e se interiorizarem, estes perceberam uma grande diferença climática nessa região semiárida. Assim, chamaram-na de "desertão", em virtude do seu clima quente e seco. Logo, essa denominação foi sendo entendida como "de sertão", permanecendo, com o passar do tempo, apenas a palavra "sertão". Por sua vez, a região sertaneja semiárida estende-se pelos estados da Bahia, Pernambuco, Paraíba, Rio Grande do Norte e Piauí, abrangendo também o Ceará, Sergipe e Alagoas, além da região Norte do estado de Minas Gerais, o Vale do Jequitinhonha. "Sertão" seria utilizado também em antagonismo a "capital", pela sua referência simbólica ao interior dos estados. Uma informação interessante é a de que Fortaleza, no Ceará, é a única capital brasileira localizada dentro da área de abrangência do sertão semiárido. ${ }^{4}$

Portanto, o meio rural em geral, e o sertão semiárido em particular, podem ser definidos como tradicionais "áreas de exclusão", onde o sistema capitalista mantém formas arcaicas e extremadas de exploração da classe trabalhadora, com o desrespeito, até mesmo, aos direitos sociais já conquistados na Constituição de 1988 e mesmo no Estado Novo (dentre eles, o direito à educação, à saúde e à CLT, por exemplo), configurando uma "questão social agrária" bastante problemática.

Nota-se, portanto, que a relação existente entre educação e meio rural é basicamente de funcionalidade: só se educa àqueles que supostamente terão alguma utilidade para a sociedade capitalista industrializada. Nesta lógica, o analfabeto adulto, o trabalhador rural e os demais povos do campo (cf. CALDART, 2008) não precisam ser educados. Conforme explica Vieira Pinto (2005):

\begin{abstract}
A sociedade empreende a alfabetização de adultos fundamentalmente para poder integrá-los num nível superior de produção. Já temos dito que não se trata de dever moral de obras de caridade, e sim de uma imperiosa exigência social. A sociedade precisa educar seus adultos, desde que alcance um nível de desenvolvimento que torne incompatível a existência de segmentos marginalizados em seu seio, que podem aumentar a força de trabalho geral se forem convertidos em trabalhadores letrados num nível alto de conhecimento. (...) Uma lei do desenvolvimento educacional é esta: a sociedade nunca desperdiça seus recursos educacionais (econômicos e pessoais), apenas proporciona educação nos estritos limites de suas necessidades objetivas. Não educa ninguém que não precise educar (p. 102-103).
\end{abstract}

Talvez isso justifique, mesmo que parcialmente, a exclusão educacional que acomete especialmente os residentes nas regiões rurais. Por isso, acredito não ser possível desvincular EJA de alfabetização e, mesmo que indiretamente, de educação no campo. Enquanto não houver uma estrutura que garanta (realmente) acesso à educação pública nas regiões menos desenvolvidas do país, novos analfabetos estarão sendo gerados.

Sabe-se, porém, que as iniciativas de "alfabetização em massa" que foram instituídas no país, principalmente na década de 1970, das quais o Movimento Brasileiro de Alfabetização (MOBRAL) foi o mais conhecido, estiveram carregadas de uma forte orientação política-ideológica, que se centrava na legitimação da ordem social instituída, regida pela "ditadura do grande capital", utilizando uma expressão do sociólogo Octávio Ianni (1981). 
O estudo desenvolvido por Paiva (2003) mostra que, nestas ações de alfabetização empreendidas pelo MOBRAL, difundia-se entre os alunos uma ideologia de responsabilização pessoal pelo sucesso ou fracasso escolar obtido. Com isso, a própria condição de analfabetismo passou a ser estigmatizada e vista de forma depreciativa pela sociedade em geral, gerando nos adultos que não sabiam ler e escrever um sentimento de culpa e vergonha. Além disso, e de forma coerente aos propósitos de controle do governo militar, instituiu-se, via MOBRAL, um processo de adestramento e disciplinamento das camadas populares, no intuito de incitar nelas um nacionalismo alienado de "amor à pátria" e evitar a disseminação, entre elas, das "ideias subversivas" do comunismo/socialismo, vinculadas à teoria marxista.

Nos dias de hoje, o analfabetismo ainda é normalmente tratado como responsabilidade pessoal dos analfabetos. O Estado procura, ao máximo, se eximir dessa responsabilidade, atribuindo, primeiramente, à família - portanto, à esfera privada e pessoal - o dever de educar, conforme podemos ver na LDB (Lei 9394/96, artigo $2^{\circ}$ ). A educação de jovens e adultos (EJA), citada na LDB como alternativa educacional destinada "àqueles que não tiveram acesso ou continuidade de estudos no ensino fundamental e médio na idade própria" (Art. $37^{\circ}$ ), ainda é tratada com menosprezo pelas políticas educacionais. Não podemos esquecer que, como a população rural é a que mais necessita da oferta de EJA, a precariedade desta modalidade de educação está diretamente vinculada à ausência e/ou à má qualidade das escolas nas áreas rurais.

Para Caldart (2008), embora o problema da educação brasileira não seja apenas no campo, é aí que a situação se torna mais grave, pois além de desconsiderar a realidade escolar existente, que é bastante diferente da que é vivida nos grandes centros urbanos, essa forma de educação sempre foi tratada pelo poder público com políticas compensatórias (de caráter paliativo), e sem um compromisso efetivo de adaptação da educação às peculiaridades do meio rural. Podemos pensar, ainda, que nas regiões rurais é onde há uma maior necessidade de políticas de educação de adultos, especialmente as de alfabetização. Contudo, elas não ocorrem.

Tradicionalmente, a escola foi concebida como uma invenção da sociedade capitalista industrial em geral, e da cidade em particular, destinada a preparar as elites para governar e a camada popular para ser mão de obra (portanto governada). Por isso, o campo não se constituiu historicamente como espaço prioritário para ações institucionalizadas do Estado, através de diferentes políticas públicas e sociais, e nem de políticas econômicas de desenvolvimento local e regional. Nessa perspectiva, o campo é pensado numa relação "não hegemônica" de educação, ou seja, que se situa à margem da perspectiva urbanoindustrial da sociedade capitalista (CALDART, 2008).

O meio rural é então representado como um espaço caracterizado por uma realidade geográfica e uma formação histórica e cultural singulares aos sujeitos que o compõe, ou seja, camponeses, agricultores e extrativistas (assentados, sem terra, ribeirinhos), trabalhadores do campo (assalariados, meeiros, etc.), pescadores, quilombolas, caiçaras, indígenas e povos da floresta. Assim, o desprezo pela vida rural e suas peculiaridades, verificado nas leis e políticas educacionais, é análogo à exclusão histórica vivida pelos povos do campo no Brasil.

\section{A UFERSA e as políticas afirmativas: uma mão estendida no abismo do semiárido}

As políticas afirmativas na educação superior devem ser analisadas de forma mais cuidadosa em contextos como o da região Nordeste, especialmente o semiárido, como 
tradicional área de exclusão, e na qual há predominância do rural sobre o urbano. Aí se concentram populações excluídas, tanto pela sua condição socioeconômica, quanto pelo seu perfil étnico-racial. As políticas afirmativas, como as cotas raciais e os programas de acesso e permanência para alunos de escola pública, são tidas, por muitos, como oportunidades raras de ascensão social.

\begin{tabular}{|l|c|c|}
\hline \multicolumn{3}{|c|}{ Tabela 3 - Distribuição dos bolsistas do Programa Conexões de Saberes da UFERSA } \\
campus Mossoró por sexo - Ano de 2010
\end{tabular}

Fonte: Questionários socioeconômicos da Pró-Reitoria de Extensão e Cultura da UFERSA, 2010.

O Programa Conexões de Saberes da UFERSA é um exemplo peculiar e diferenciado de política afirmativa, por contemplar estudantes originários do sertão semiárido, tradicional área de exclusão. Sem sombra de dúvidas, é uma ação afirmativa extremamente necessária, apesar de tímida e incipiente. Contudo, pelo menos algo está sendo feito na tentativa de superar a exclusão social.

Quando se analisa o perfil dos alunos bolsistas do Programa Conexões de Saberes da UFERSA, toma-se consciência da sua vulnerabilidade social. A Tabela 3 mostra que, dentre os participantes, a maioria (56\%) é do sexo masculino, contra $44 \%$ do sexo feminino. Estes dados podem revelar as maiores oportunidades de acesso dos homens das classes populares ao ensino superior, o que pode ser explicado, em parte, pela condição desprivilegiada vivida pelas mulheres desta classe, a quem ainda é atribuída fortemente a responsabilidade doméstica e familiar, especialmente num contexto patriarcal, patrimonialista e excludente como o do sertão semiárido. Caldart (2008) mostra que a exclusão da mulher camponesa é bem mais intensa do que a ocorrida no meio urbano, em razão das dificuldades socio-históricas de se estender para o meio rural os direitos sociais e constitucionais que defendem a mulher no Brasil.

Tanto a precariedade da educação oferecida no campo, quanto a inexistência, no meio rural, de instâncias protetoras de direitos das mulheres (como delegacias da mulher, tribunais de justiça e ministério público, por exemplo), são determinantes da maior exclusão e vulnerabilidade social da mulher neste contexto. Soma-se a isso o caráter reprodutor e coercitivo da tradição machista, inerente à cultura patriarcal, dos espaços sócio-geográficos "não industrializados", marcados por uma "solidariedade mecânica", conforme definição da sociologia positivista de Émile Durkheim (2008), dificultando sobremaneira a emancipação da mulher e a sua inclusão educacional. 


\begin{tabular}{|l|c|c|}
\hline \multicolumn{3}{|c|}{ Tabela 4 - Distribuição dos bolsistas do Programa Conexões de Saberes da UFERSA } \\
campus Mossoró por cor ou etnia - Ano de 2010
\end{tabular}

Fonte: Questionários socioeconômicos da Pró-Reitoria de Extensão e Cultura da UFERSA, 2010.

Já na Tabela 4, percebe-se a predominância de estudantes de cor parda (52\%), contra $40 \%$ de brancos e $4 \%$ de pretos e amarelos. No Nordeste, onde predomina a miscigenação racial, a cor parda é de fato predominante. Porém, é notório que a maioria dos estudantes de classe popular seja de cor parda, considerando o fato de que, em todo o território nacional, 97\% dos universitários são brancos, conforme dados levantados por um estudo de Kabengelê Munanga (2003). Desta forma, somente 2\% dos negros têm acesso ao ensino superior. Os outros 1\%, são representados pelos orientais. Estes números revelam que, dentre os mais carentes, a maioria ainda é preta ou parda e, dentre estes, os pardos ainda estão em condições menos desfavoráveis do que a população negra. Assim, a exclusão educacional que afeta mais diretamente a população negra é um problema de miséria social, que envolve políticas sociais e também de geração de emprego e renda.

\begin{tabular}{|l|c|c|}
\hline \multicolumn{3}{|c|}{$\begin{array}{c}\text { Tabela 5 - Distribuição dos bolsistas do Programa Conexões de Saberes da UFERSA } \\
\text { campus Mossoró por renda familiar - Ano de 2010 }\end{array}$} \\
\hline Renda familiar & Porcentagem & Quantidade \\
\hline Até 1 SM & $32 \%$ & 8 \\
\hline De 1 a 2 SM & $24 \%$ & 6 \\
\hline De 2 a 4 SM & $44 \%$ & 11 \\
\hline
\end{tabular}

Fonte: Questionários socioeconômicos da Pró-Reitoria de Extensão e Cultura da UFERSA, 2010.

A precária condição socioeconômica dos estudantes é revelada especialmente pela sua renda familiar, mostrada na Tabela 5. Entre os participantes do Programa, 32\% possuem renda familiar de até 1 salário mínimo, 24\% de 1 a 2 salários mínimos e $44 \%$ de 2 a 4 salários mínimos. Em síntese, pode-se dizer que a maioria $(56 \%)$ vive com renda familiar menor do que 2 salários mínimos. De acordo com Kabengelê Munanga (2003), sobre 22 milhões de brasileiros que vivem abaixo da linha de pobreza, $70 \%$ deles são negros. E sobre 53 milhões de brasileiros que vivem na pobreza, 63\% deles são negros. Assim, nota-se que, no Brasil, negritude e pobreza ainda estão diretamente relacionadas, conforme resalta Florestan Fernandes (2008), em seu trabalho sobre A integração do negro na sociedade de classes. 
O vínculo sócio-histórico entre negritude e pobreza no Brasil se reflete na exclusão educacional que afeta mais a população negra e parda, do que a população branca. Numa sociedade extremamente desigual como a brasileira, que possui um dos piores níveis de concentração de renda do mundo, certamente haverá inúmeros entraves à inserção do negro nas instituições educacionais e no mercado de trabalho. Se no Brasil não foi oferecida ao negro liberto da condição de escravidão, e nem aos seus descendentes, condições efetivas para que estes pudessem se inserir à "sociedade de classes", sem dúvida é urgente hoje a adoção de políticas de ação afirmativa, das cotas raciais e para estudantes de escolas públicas, visando o seu acesso e permanência nas universidades federais e estaduais.

Tabela 6 - Distribuição dos bolsistas do Programa Conexões de Saberes da UFERSA campus Mossoró por situação de moradia - Ano de 2010

\begin{tabular}{|l|c|c|}
\hline Condição de moradia em Mossoró & Porcentagem & Quantidade \\
\hline Vila Acadêmica & $28 \%$ & 7 \\
\hline República & $12 \%$ & 3 \\
\hline Casa/apto. alugado & $12 \%$ & 3 \\
\hline Com parentes/amigos & $12 \%$ & 3 \\
\hline Com a família & $36 \%$ & 9 \\
\hline
\end{tabular}

Fonte: Questionários socioeconômicos da Pró-Reitoria de Extensão e Cultura da UFERSA, 2010.

Contudo, é necessário não se perder de vista que o problema maior da questão da exclusão educacional (de negros, pardos e pobres) é a má qualidade da escola pública básica no Brasil, a que abrange ensino fundamental e médio, ou seja, a porta de entrada para a vida escolar. É preciso ter consciência de que as cotas para o ensino superior são só medidas emergenciais e paliativas, e que não são capazes, por si só, de resolver um problema que não é propriamente da universidade e sim da escola básica pública. Além disso, as cotas não são totalmente justas e equitativas, pois nem todas as escolas públicas de ensino fundamental e médio são iguais no aspecto qualitativo. Não é possível se comparar, por exemplo, o nível de ensino de uma escola pública localizada numa capital ou num grande centro urbano (como São Paulo), com outra escola que pertence à zona rural de uma pequena cidade do interior do Nordeste. Assim, nota-se que há exclusão e disparidade mesmo dentro da própria política de cotas.

Ademais, a precariedade vivida pelos estudantes-bolsistas dos programas de ações afirmativas é refletida também pela sua dependência no que refere à moradia, que é um dos quesitos fundamentais da política de permanência no ensino superior público, conforme é verificado na Tabela 6. Dentre o total de bolsistas do Programa Conexões de Saberes da UFERSA, nota-se que $28 \%$ deles dependem da Vila Acadêmica, que é uma moradia estudantil gratuita, oferecida pela universidade, e cuja seleção de beneficiados é realizada a partir da comprovação de renda pelos estudantes. O fato de $36 \%$ morarem com a família, contra $12 \%$ que moram em república, com parentes e amigos e/ou em apartamento alugado, também revela o grau de dependência econômica destes estudantes, que não é 
suprido totalmente pelas políticas de permanência, considerando que as moradias estudantis são insuficientes para atender a todos os que precisam delas.

\begin{tabular}{|l|c|c|}
\hline \multicolumn{2}{|c|}{$\begin{array}{c}|c| \\
\text { Tabela } 7 \text { - Distribuição dos bolsistas do Programa Conexões de Saberes da UFERSA } \\
\text { campus Mossoró por origem (rural/urbana) - Ano de } 2010\end{array}$} \\
\hline Origem & Porcentagem & Quantidade \\
\hline Zona urbana & $88 \%$ & 22 \\
\hline Zona rural & $12 \%$ & 3 \\
\hline
\end{tabular}

Fonte: Questionários socioeconômicos da Pró-Reitoria de Extensão e Cultura da UFERSA, 2010.

Ademais, o fato de $88 \%$ de os estudantes de origem popular ser provenientes do que se convencionou chamar de "zona urbana", contra $12 \%$ da zona rural, conforme vemos na Tabela 7, pode ser questionado. No Brasil, a classificação dos municípios e demais localidades como urbano ou rural é realizada com certa imprecisão pelo IBGE, conforme revela o estudo de Veiga (2003), intitulado Cidades imaginárias: o Brasil é menos urbano do que se calcula. Para o autor, a classificação oficial feita pelo IBGE é realizada com base em critérios pouco confiáveis, sem um estudo pormenorizado da dinâmica econômica, estrutural e demográfica das localidades. Assim, um município de 9 mil habitantes, localizada no interior do Pará, por exemplo, com uma economia basicamente rural, é classificada erroneamente como zona urbana.

Há de se considerar também que os municípios que integram o semiárido nordestino, caso de Mossoró e das demais cidades do interior do Rio Grande do Norte, estão entre os de menor índice de desenvolvimento humano (IDH) do Brasil. Estes municípios são quase 40\% (397) dos 1.000 de menor IDH, segundo o Programa das Nações Unidas para o Desenvolvimento (PNUD) de 2005. Esta realidade se deve, exatamente, à precariedade de acesso aos direitos sociais básicos, como saúde, educação, moradia, segurança, trabalho, etc. Números obtidos pelo Atlas do Desenvolvimento Humano no Brasil de 2000 revelam que $81,8 \%$ dos municípios do semiárido brasileiro, com $61,7 \%$ da população, têm baixo IDH. Nenhum município do semiárido está na faixa mais elevada de IDH (entre 0,800 e 1,000). Diante desse quadro de elevada concentração de renda, alguns autores, como Silva (2007), defendem a necessidade do estabelecimento de políticas públicas específicas, direcionadas à promoção do desenvolvimento regional nos aspectos social e humano e tendo como fim a obtenção de maior justiça social. Essa precariedade social vivida no semiárido deve, sem dúvida, ser levada em consideração quando da elaboração de políticas afirmativas relacionadas ao acesso e permanência no ensino superior público.

Desta forma, os municípios do interior do Rio Grande do Norte, com exceção de Mossoró, podem ser classificados como áreas essencialmente rurais. Desta forma, a referência quanto à origem urbana ou rural, realizada pelos bolsistas, não é precisa. As características socioeconômicas e demográficas que apresentam são típicas de indivíduos provenientes de zona rural. Contudo, o fato de somente $12 \%$ terem declarado que são de origem rural também merece atenção especial. Em primeiro lugar, se alguns afirmaram ser de zona urbana, enquanto outros de zona rural, isso significa que, independente da precisão da classificação (urbana/rural), os que são provenientes da zona rural enfrentaram uma 
precariedade ainda maior, no que se refere à estrutura do sistema educacional que freqüentaram.

Por isso, é certamente questionável a idéia de que as políticas compensatórias, como as cotas para estudantes de escolas públicas, por exemplo, promovem uma maior justiça social e equidade no acesso ao ensino superior público. $\mathrm{Na}$ verdade, não representam oportunidades iguais para todos. Isso porque alunos de escolas públicas localizadas na zona rural não dispõem da mesma qualidade de ensino oferecida pelas escolas da zona urbana. E como não há ainda "cotas para estudantes da zona rural", as políticas afirmativas hoje vigentes certamente são desfavoráveis aos alunos das escolas rurais. A menor quantidade de estudantes originários da zona rural pode ser um importante indicativo da maior exclusão educacional vivida por eles, mesmo com a existência das políticas de cotas.

\begin{tabular}{|l|c|c|}
\hline \multicolumn{2}{|c|}{$\begin{array}{c}\text { Tabela 8 - Distribuição dos bolsistas do Programa Conexões de Saberes da UFERSA } \\
\text { campus Mossoró por trajetória educacional - Ano de } 2010\end{array}$} \\
\hline Ensino médio & Porcentagem & Quantidade \\
\hline Escola pública & $92 \%$ & 23 \\
\hline Escola particular & $8 \%$ & 2 \\
\hline
\end{tabular}

Fonte: Questionários socioeconômicos da Pró-Reitoria de Extensão e Cultura da UFERSA, 2010.

A Tabela 8 mostra que os estudantes que cursaram escola pública ainda predominam dentre os participantes do Programa, representando $92 \%$ do total. Os $8 \%$ que estudaram em escolas privadas, foram beneficiados por bolsas de estudo. Isso revela que as classes populares ainda dependem especialmente da escola pública como veículo de ascensão social, pois não têm condições de pagar por serviços educacionais particulares, geralmente de qualidade superior. A situação se inverte quando se considera a realidade das universidades públicas no país, que têm a maioria de seus alunos provenientes de escolas privadas.

O acesso à universidade pública é, portanto, para muitos estudantes de origem popular, a única oportunidade de ascensão social que terão ao longo da vida, uma vez que dificilmente poderão pagar pelos cursos de graduação de faculdades privadas, cada vez mais caros. Principalmente para estudantes negros, afro-descendentes e pardos, que dependem massivamente das escolas básicas públicas, as políticas afirmativas no ensino superior (apesar de não serem plenamente equitativas, pela própria diferença qualitativa existente entre as escolas rurais e urbanas, conforme já explicamos) representam, sem nenhuma dúvida, novas possibilidades. E, obviamente, possibilidades é melhor tê-las do que não tê-las.

Utilizando como referência de comparação a realidade das políticas afirmativas educacionais nos Estados Unidos, Kabengelê Munanga (2003) explica que:

Uma coisa é certa, os negros que ingressarão nas universidades públicas de boa qualidade pelas cotas terão, talvez, uma oportunidade única na sua vida: receber e acumular um conhecimento científico que os acompanhará no seu caminho da luta pela sobrevivência. Apesar dos preconceitos que persistirão ainda por muito tempo, eles serão capazes de 
se defender melhor no momento das grandes concorrências e nos concursos públicos a exibir certo conhecimento que não dominavam antes. Abrirão com facilidade algumas portas, graças a esse conhecimento adquirido e ao restabelecimento de sua autoestima. A história da luta das mulheres ilustra melhor o que seria o futuro dos negros. A discriminação contra elas não foi totalmente desarmada, mas elas ocupam cada vez mais espaços na sociedade não porque os homens se tornaram menos machistas e mais tolerantes, mas porque, justamente graças ao conhecimento adquirido, elas demonstram competências e capacidades que lhes abrem as portas antigamente fechadas. $\mathrm{O}$ racismo contra negros não recuou nos Estados Unidos. Mas hoje, graças ao conhecimento adquirido com cotas, eles tiveram uma grande mobilidade social, jamais conhecida antes (p. 02).

\begin{tabular}{|c|c|c|}
\hline Cursos de graduação & Porcentagem & Quantidade \\
\hline Administração de Empresas & $4 \%$ & 1 \\
\hline Agronomia & $20 \%$ & 5 \\
\hline BCT & $36 \%$ & 9 \\
\hline Ciências Contábeis & $4 \%$ & 1 \\
\hline Direito & $8 \%$ & 2 \\
\hline Ecologia & $4 \%$ & 1 \\
\hline Engenharia Agrícola & $4 \%$ & 1 \\
\hline Engenharia Mecânica & $4 \%$ & 1 \\
\hline Engenharia de Pesca & $4 \%$ & 1 \\
\hline Medicina Veterinária & $8 \%$ & 2 \\
\hline Zootecnia & $4 \%$ & 1 \\
\hline
\end{tabular}

Fonte: Questionários socioeconômicos da Pró-Reitoria de Extensão e Cultura da UFERSA, 2010.

De fato, se, por um lado, a situação de exclusão social vivida pelas classes populares não será solucionada milagrosamente pelas políticas afirmativas, por outro, o efeito de longo prazo da integração dos estudantes de origem popular nas universidades públicas pode produzir efeitos bastante positivos. Ela pode reduzir a desigualdade, ao criar possibilidades, tanto aos negros e aos seus descendentes, quanto às mulheres e aos demais estudantes de origem popular. Em nenhum outro país do mundo podemos ver uma população negra tão bem-sucedida como nos Estados Unidos. E isso se deve, em grande parte, às políticas de cotas raciais adotadas nas universidades norte-americanas. Levando 
em conta, obviamente, as diferenças étnico-raciais, sociais e culturais entre Brasil e Estados Unidos, algo semelhante se pode esperar das políticas afirmativas e das cotas no ensino superior público brasileiro.

Conforme podemos ver na Tabela 9, a predominância de bolsistas do Programa Conexões de Saberes no curso de Bacharelado em Ciência e Tecnologia (BCT), que foi criado recentemente pelo MEC, retrata outra possibilidade de acesso ao ensino superior decorrente de ações afirmativas. Como tem duração de três anos, o BCT, na realidade, visa atender a uma necessidade das classes populares: a de graduar-se em menor tempo. Aliás, essa tem sido uma tendência do governo federal petista, investindo ultimamente na criação e ampliação de Institutos Federais de Educação Tecnológica, com cursos de graduação na modalidade tecnólogos, com a duração de três anos. Estes cursos visam suprir a demanda das empresas por profissionais com conhecimento técnico, ao mesmo tempo em que cria oportunidades para estudantes de origem popular. É, no fundo, uma estratégia de qualificação da classe trabalhadora, com o intuito de evitar a sua revolta e mobilização política. Conforme mostra Vieira (1987), com a promoção de políticas sociais ineficazes, o Estado busca neutralizar estrategicamente as lutas de classes.

\section{Considerações finais}

A análise aqui desenvolvida revela a importância das políticas afirmativas educacionais do governo federal, particularmente o Programa Conexões de Saberes da UFERSA. Os dados coletados mostram a situação socioeconômica precária dos estudantes de origem popular, selecionados como bolsistas do Programa. A exclusão social e também educacional de que foram vítimas ao longo da vida justificam a necessidade das políticas afirmativas, comprometidas com o acesso e a permanência de estudantes de origem popular nas universidades. Neste panorama, há de se considerar também que a própria estrutura da educação básica no Brasil é extremamente desigual. Tal desigualdade, no entanto, não se limita à disparidade existente entre escola pública e escola privada, mas também entre as próprias escolas públicas, ao compararmos a as escolas rurais com as urbanas, por exemplo, no que se refere à qualidade do ensino oferecido e ao nível de acesso e permanência.

Apesar das críticas existentes às políticas afirmativas na educação superior brasileira - por exemplo, de que são soluções paliativas para um problema estrutural mais complexo, que envolve a própria qualidade da escola básica pública, de que são um tipo de "racismo às avessas", ou um "atestado de incapacidade" da parte dos negros, afrodescendentes e dos estudantes oriundos de escolas públicas -, tais políticas têm se revelado de grande importância para inúmeros estudantes de origem popular. Muitos negros e pardos, afro-descendentes, indígenas, quilombolas e demais indivíduos (jovens e adultos) em situação de miséria social dependem das políticas afirmativas como única oportunidade de ascensão social que terão ao longo da vida.

E ao levarmos em consideração regiões caracterizadas pela miséria social e pela exclusão educacional, como é o caso do semiárido nordestino, as políticas afirmativas de acesso e permanência no ensino superior público se fazem necessárias. Contudo, é indispensável que sejam criadas também estratégias de ação política para melhorar o acesso e a permanência dos estudantes de origem popular na educação básica pública, além de fazer com que esta modalidade de educação seja de qualidade compatível com a oferecida nas escolas particulares, e que as disparidades entre campo e cidade sejam minimizadas. 
Um governo federal que pretende ser (realmente) de base popular deveria contemplar a amplitude das demandas educacionais, incluindo na pauta os excluídos da educação, como os analfabetos e os adultos que abandonaram o ensino fundamental ou médio. E é aí que se faz necessário investir em políticas de educação de jovens e adultos (EJA), que é destinada a estes grupos excluídos. Evidentemente, é a educação fundamental a modalidade mais diretamente relacionada aos sujeitos em situação de miséria social, como trabalhadores rurais, trabalhadores urbanos braçais (como construção civil e limpeza, por exemplo), crianças e jovens moradores da zona rural e das periferias urbanas, favelados, órfãos, moradores de rua, dentre outros. A estes cidadãos também precisa ser dada garantia de acesso e permanência na educação fundamental, que é a "porta de entrada" da trajetória educacional em nossa sociedade.

$\mathrm{Na}$ verdade, é preciso combater a exclusão educacional em todas as suas dimensões, e acredito que o analfabetismo e a evasão escolar na educação fundamental seja um problema bastante grave, e que tem sido esquecido diante da efervescência do debate sobre acesso e permanência no ensino superior brasileiro. Contudo, os sujeitos excluídos da educação fundamental padecem de uma situação de vulnerabilidade social sem dúvida mais preocupante do que os que puderam ao menos concluir o ensino médio e já estão pensando na possibilidade de ingressarem na universidade.

No entanto, apesar das falhas e aspectos negativos que acompanham os programas de política afirmativa nas universidades brasileiras, como o Programa Conexões de Saberes, não podemos "jogar a criança junto com a água do banho", usando aqui uma conhecida expressão popular. Em verdade, as políticas afirmativas representam oportunidades únicas de inclusão educacional e ascensão social para muitos jovens oriundos das classes menos favorecidas e de contextos marcados pela precariedade estrutural e pela exclusão social, como é o caso do sertão semiárido do Estado do Rio Grande do Norte. Aí, qualquer forma de educação popular e de inclusão educacional (e social), que seja séria e eficiente, sem dúvida é bem vinda.

\section{Referências:}

ALBUQUERQUE JR. Durval. A invenção do Nordeste e outras artes. São Paulo: Cortez, 1999.

ATLAS DO DESENVOLVIMENTO HUMANO NO BRASIL, 2000.

CALDART, Roseli. Por uma educação do campo. Petrópolis: Vozes, 2008.

DURKHEIM, Émile. Da divisão do trabalho social. São Paulo: Martins Fontes, 2008.

FABRINI, João. As manifestações coletivas e comunitárias como componentes da resistência camponesa. In: Anais do $\mathbf{X}$ Encontro de Geógrafos da América Latina, FFLCH-USP, São Paulo, março de 2005.

FERNANDES, Florestan. A integração do negro na sociedade de classes. São Paulo: Globo, 2008.

IANNI, Octávio. A ditadura do grande capital. Rio de Janeiro: Civilização Brasileira, 1981.

IBGE, Censos 2000 e 2010.

INEP. Panorama da educação do campo. Brasília/DF, 2007.

LDB - Lei 9394/96. 
MUNANGA, Kabengelê. Políticas de ação afirmativa em benefício da população negra no Brasil: um ponto de vista em defesa de cotas. Revista Espaço Acadêmico, n. 22, mar./2003. Disponível em: www.espacoacademico.com.br/022/22cmunanga.htm (acessado em 07/08/2011).

PAIVA, Vanilda. História da educação popular no Brasil. São Paulo: Loyola, 2003.

PINTO, Álvaro. Sete lições sobre educação de adultos. São Paulo: Cortez, 2005.

PROGRAMA DAS NAÇÕES UNIDAS PARA O DESENVOLVIMENTO, 2005.

RAMOS, Graciliano. Vidas secas. Rio de Janeiro: Record, 2008.

SILVA, Roberto. Entre o combate à seca e a convivência com o semiárido: políticas públicas e transição paradigmática. In: Revista Econômica do Nordeste, Fortaleza, vol. 38, n. 3, jul-set. 2007, p. 466-485.

VEIGA, José. Cidades imaginárias: o Brasil é menos urbano do que se calcula. Campinas/SP: Autores Associados, 2003.

VIEIRA, Evaldo. Estado e miséria social no Brasil: de Getúlio a Geisel. São Paulo: Cortez, 1987.

Notas:

\footnotetext{
${ }^{1}$ Doutor em Educação pela USP. Mestre em Sociologia pela UNICAMP. Ex-professor da UFERSA, campus de Mossoró/RN (2009-2011). Atualmente, é professor adjunto da UESC, campus de Ilhéus/BA. Contato: mperes@usp.br

${ }^{2}$ Professora Assistente da Universidade Federal Rural do Semi-Árido (UFERSA), campus de Angicos/RN. Mestre em Estudos da Linguagem pela Universidade Federal do Rio Grande do Norte (UFRN). Doutoranda em Estudos da Linguagem pela UFRN. Atuou como Coordenadora Geral do Programa Conexões de Saberes na UFERSA (2010-2012).

${ }^{3}$ Merece destaque o fato de que as regiões semiáridas possuem um dos piores índices de desenvolvimento humano (IDH) do país, conforme mostra o relatório do Programa das Nações Unidas para o Desenvolvimento (PNUD) de 2005.

${ }^{4}$ Cf. http://www.cliquesemiarido.org.br/
}

Recebido em novembro/2011

Aprovado em março/2012 